\title{
O PRINCÍPIO FUNCIONAL/COGNITIVO DA \\ ESTRUTURA DA INFORMAÇÃO E MECANISMOS SINTÁTICOS EM UM CONTEXTO DE APRENDIZAGEM DE INGLÊS COMO L2
}

\section{THE FUNCTIONAL/COGNITIVE PRINCIPLE OF INFORMATION STRUCTURE AND SYNTACTIC DEVICES IN A CONTEXT OF ENGLISH AS L2 LEARNING}

\section{Adriana Maria Tenuta de Azevedo* Ana Larissa Adorno Marciotto Oliveira}

\section{RESUMO}

Este artigo tem por objetivo apresentar os resultados de uma pesquisa realizada com o intuito de se investigar se os aprendizes de inglês como segunda língua (L2) reconhecem, implícita e/ou explicitamente, a existência do princípio funcional/ cognitivo de distribuição da informação em um texto. A pesquisa também verificou o domínio, por esses aprendizes, de alguns dispositivos sintáticos relacionados às estruturas da informação e temática, que são usados para se atenderem a demandas comunicativas específicas. O referencial teórico baseia-se nos princípios da linguística funcional e conceitos ligados à cognição, em relação aos impactos da organização discursiva sobre escolhas linguísticas (Halliday, 1973; Chafe, 1995). O corpus desta pesquisa consistiu em uma série de exercícios que foram administrados aos alunos de graduação da habilitação em inglês. As descobertas lançam luz sobre o fato de que os alunos ainda não estão conscientes de vários processos que envolvem arranjos gramaticais e o fluxo do discurso, assim como eles não percebem bem como a gramática pode impactar a intenção comunicativa de um texto escrito.

Palavras-chave: tema e rema; dado e novo; discurso.

\section{ABSTRACT}

This paper aims at presenting the results of a study carried out in order to investigate whether learners of English as a second language (L2) recognize, implicitly and / or explicitly, the existence of the functional / cognitive principle of distribution of information in a text. The study also aimed at investigating whether learners

\footnotetext{
*UFMG, Belo Horizonte (MG), Brasil. atenuta@gmail.com, UFMG, Belo Horizonte (MG), Brasil. adornomarciotto@gmail.com

Parte dos resultados da pesquisa relatada neste artigo foi apresentada no ICLC 2013, em Edmonton, Canadá.
} 
were aware of the processes involving some syntactic arrangements, relative to the thematic and informational structure of a text, which are used to meet specific communicative demands. The theoretical background relies on the principles of functional-cognitive linguistics, relative to how discourse impacts linguistic choices (Halliday, 1973; Chafe 1995). The corpus of this research consisted of a series of exercises that were administered to undergraduate students, English majors. The findings shed light to the fact that learners are still unaware of most processes involving grammar arrangements and the discourse flow, as they are not very conscious of how grammar can impact the communicative intent of a written text.

Keywords: theme and rheme; given and new; discourse.

\section{PANORAMA DO ESTUDO}

Este trabalho tem por objetivo apresentar os resultados de uma pesquisa realizada com a finalidade de se investigar se os aprendizes de inglês como segunda língua (L2) reconhecem, implícita e/ou explicitamente, a existência do princípio funcional/cognitivo de distribuição da informação em textos. ${ }^{1}$ A pesquisa também verificou o domínio, por esses aprendizes, de alguns dispositivos sintáticos relacionados às estruturas da informação e temática, que são usados para se atenderem a demandas comunicativas do discurso. Esse fenômeno da interrelação entre a estrutura sintática e o discurso reflete uma interligação entre a utilização da linguagem e a cognição humana através de processos de atenção e foco.

Investigou-se, pela pesquisa realizada, se os alunos estão aptos para atenderem às demandas discursivas, sendo capazes de realizar arranjos sintáticos nas orações que sejam contextualmente adequados. Voltou-se também para a questão de os alunos estarem ou não conscientes do fato de que há, nos textos, uma estrutura de informação, que envolve os conceitos de informação dada e informação nova, assim como há uma estrutura temática, que abrange os conceitos de tema e rema

Para isso, a pesquisa teve, como sujeitos, alunos de graduação da habilitação Inglês da Faculdade de Letras da UFMG, em nível intermediário. O corpus da pesquisa consistiu de uma série de exercícios aplicados a esses alunos, a fim de se descobrir se eles reconheciam o princípio da distribuição de informação e se eram capazes de explicá-lo. Esse princípio é mencionado por Rutherford (1987) e representa os padrões de estruturação temática apresentados por McCarthy (1991), apresentados neste artigo. Portanto, os exercícios aplicados aos alunos

\footnotetext{
1 Pesquisa semelhante foi realizada anteriormente por uma das autoras (TENUTA, 2001) e a realização desta pesquisa foi pensada no sentido de se poder fazer uma comparação, de vários dos aspectos discutidos, nos dois momentos de checagem.
} 
visaram à verificação da percepção geral desses aprendizes da necessidade de se mudarem ou moverem eventualmente alguns componentes da oração a fim de que exigências específicas do discurso sejam atendidas. Investigou-se, também, se os participantes da pesquisa tinham consciência do fato de que um certo conteúdo proposicional pode ser expresso através de diferentes estruturas nominais e verbais, sendo realizado por meio de diferentes papéis temáticos. O presente estudo teve, ainda, por objetivo a verificação da existência, na interlíngua desses alunos, de algumas das características mencionadas por Rutherford (1987) como sendo típicas da produção linguística de aprendizes de inglês como L2. A pesquisa contou com 46 participantes.

A nossa hipótese é a de que os alunos de inglês como segunda língua têm pouca consciência da interação entre sintaxe e discurso, ou seja, eles não estão cientes do princípio funcional/cognitivo que governa o arranjo textual. Além disso, eles não apresentam muita consciência das possibilidades sintáticas para movimentos de constituintes (ou conhecimento de construções alternativas) disponíveis na língua inglesa, que possibilitam o falante/escritor atender às demandas da organização discursiva. Foi nossa hipótese, também, que a interlíngua desses aprendizes compartilha das características apresentadas por Rutherford (1987).

Na próxima seção, vamos apresentar e discutir os conceitos ligados à estrutura da informação e à estrutura temática. Vamos também abordar a noção cognitiva de atenção, que é de particular interesse para este estudo.

\section{A ESTRUTURA DA INFORMAÇÃO E A ESTRUTURA TEMÁTICA}

A informação em um texto escrito é organizada, ou distribuída, em termos de elementos dados e elementos novos. Assim, a estrutura de informação no texto, no âmbito teórico dos estudos funcionais da linguagem, é vista como um processo de interação entre o que é elemento conhecido e o que é elemento novo para os usuários da língua. Nesse contexto teórico, encontram-se os conceitos de dado e novo, que referem-se, respectivamente, à informação que é recuperável a partir do contexto (verbal ou não-verbal), e à informação que não é recuperável. (PRINCE, 1981; HALLIDAY, 1985; 2004)

Nesse mesmo quadro de análise, encontramos a descrição da estrutura temática, cujos elementos constitutivos são o tema, que é definido como o ponto de partida da sentença vista como mensagem, e o rema, que é o restante dessa sentença. Considerando Halliday $(1985 ; 2004)$, compreendemos a noção de tema como 
sendo o elemento da sentença escolhido pelo falante ou escritor com a função de sinalizar a maneira como gostaríamos que as pessoas entendam o que queremos dizer. O tema é, então, uma moldura dentro da qual o ouvinte deve fazer sentido da mensagem provida pelo falante. Além disso, os usuários da língua escolhem o elemento tema de uma oração ou sentença que seja informacionalmente apropriado para aquele momento ou posição específica no discurso.

A estrutura de informação está relacionada com a estrutura temática, pois a estrutura temática reflete, em geral, demandas informacionais. O tema de uma sentença tende a ser um elemento dado, enquanto o elemento novo aparece, prototipicamente, no rema.

A estrutura temática e informacional também foram discutidas por Rutherford (1987) para explicar a maneira como a informação pode ser estruturada no discurso dos aprendizes de inglês como L2, como forma de melhor se atingirem metas específicas de comunicação. Um texto, para ser fluente e bem elaborado, deve seguir um princípio de distribuição de informação: nesse texto, tem que haver algum tipo de alternância entre a informação dada e a informação nova para que o fluxo de comunicação seja bem estabelecido. A falta de observação desse princípio pode impactar negativamente o potencial comunicativo do texto. Consequentemente, um texto é considerado bem elaborado e mais fácil de se compreender ou processar, portanto, percebido como um texto mais fluente, quando as informações dadas e novas fluem suavemente no discurso. Rutherford (1987) dá o seguinte exemplo de uma passagem produzida por um aluno:

1. (1) My father's bouse bad four bedrooms and two sitting-rooms. (2) A large garden was in front of the bouse. (3) My father bad planted a lot of flowers in the garden. (4) These flowers were roses and tulips, etc... (RUTHERFORD, 1987: 69)

Segundo o autor, podemos comparar essa passagem com uma segunda tentativa de apresentação desse conteúdo informacional, por esse mesmo aluno. O que diferencia essa segunda tentativa da primeira é a ordem da distribuição da informação em (2) e (3), como se vê a seguir:

2. (1) My father's bouse bad four bedrooms and two sitting rooms. (2) In front of the bouse was a large garden. (3) In the garden my father bad planted a lot of flowers. (4) These flowers were roses and tulips, etc... (RUTHERFORD, 1987: 69) 
$\mathrm{O}$ autor argumenta que a passagem em 2 é mais afortunada na medida em que fornece ao leitor uma melhor condição de processar a informação veiculada, já que os elementos nela apresentados no rema de uma sentença quase sempre aparecem como tema da sentença seguinte. Nessa passagem, o fluxo da informação é bem estruturado do ponto de vista da oposição entre os elementos dados e novos. Nesse contexto, o que está em julgamento é a adequação do arranjo de informações de uma sentença no nível do discurso, não a sua gramaticalidade. Por exemplo, em 1, as frases (2) e (3) são gramaticais, mas não são as melhores ligações entre (1) e (4).

Como já dito, atender ao princípio cognitivo/funcional de distribuição de informação significa fornecer uma alternância de informações dadas e novas em textos. Isso requer o conhecimento de estruturas sintáticas variadas para se fazerem escolhas adequadas de tema e rema. No geral, o atendimento a esse princípio da distribuição da informação impacta positivamente o potencial comunicativo discursivo (PRINCE, 1981; HALLIDAY, 1985; 2004), uma vez que resulta em textos que são mais fluentes e de mais fácil compreensão.

Especificamente com relação à modalidade escrita, McCarthy (1991) identificou três padrões distintos de estruturação temática, que são aqui apresentados:

(a) o tema de uma sentença contém um elemento que se torna rema na sentença seguinte:

Tema 1 Rema 1

Tema 2 = Rema 1 Rema 2

Tema 3 = Rema 2 Rema 3

(b) o tema de uma sentença tem o mesmo conteúdo referencial do tema da sentença seguinte:

Tema 1 Rema 1

Tema $2=$ Tema 1 Rema 2

Tema $3=$ Tema 1 Rema 3

(c) o rema de uma sentença contém dois (ou mais) elementos que são tomados como tema em duas (ou mais) sentenças subsequentes:

Tema 1 Rema 1 $(a+b)$

Tema $2=$ Rema 1 (a) Rema 2

Tema $3=$ Rema $1(\mathrm{~b})$ Rema 3 
Os escritores, com muita frequência, compõem textos que, naturalmente, encaixam-se em um desses padrões. Isso acontece devido ao fato de que as pessoas produzem linguagem que, do ponto de vista cognitivo, é mais adequada para fins de processamento, uma vez que o ser humano tem limitações de atenção e memória. Essa relação entre a utilização da linguagem e a cognição humana será abordada na seção seguinte.

\section{A RELAÇÃO LINGUAGEM E COGNIÇÃO}

A estrutura temática, a estrutura de informação e os arranjos sintáticos relacionam-se, assim, com a estrutura cognitiva humana, em termos de nossa capacidade de processamento (CHAFE, 1990), bem como de nossa capacidade de atenção. Padrões de distribuição de atenção foram explicados pelos linguistas cognitivos em termos de diferentes graus de relevância ou importância de um elemento no discurso. Por exemplo, as noções de foco e relevância da percepção estão na base dos conceitos de figura e fundo. Em uma determinada configuração perceptual, a figura é considerada a entidade mais saliente, ou seja, aquela que recebe um foco maior de atenção, enquanto o fundo tem uma saliência secundária, estando fora desse foco atencional. Estes conceitos vêm da Psicologia da Gestalt, e são encontrados, na linguística, em Hopper (1979), Langacker (1987; 2008), Talmy (2000), e muitos outros autores.

Seja qual for o uso que os falantes/escritores fazem das sentenças de uma língua, eles, naturalmente, colocam certos elementos em primeiro plano, em foco, para fins de atenção. Assim, existem nas línguas mecanismos linguísticos para a atribuição de foco, e a estrutura temática constitui um dos sistemas de linguagem que tem essa função e, portanto, reflete essa interrelação entre a linguagem e a capacidade cognitiva de atenção ${ }^{2}$. A relação entre o sistema cognitivo e a linguagem é apontada e/ou investigada por diversos autores, dentre os quais, Givón (1992); Landau e Jackendoff (1993); MacWhinney (1977); Osgood e Bock (1977); Langacker (1987; 2008), e Talmy (2000), que compartilham a compreensão de que a estrutura linguística (posições sintáticas) de uma sentença que expressa uma determinada cena será influenciada pela forma como o falante distribui sua atenção entre os elementos

\footnotetext{
2 Há pesquisa psicolinguística que usa priming referencial e perceptual destinada a confirmar o efeito de foco visual sobre a escolha dos elementos estruturais linguísticos (TOMLIN, 1995), confirmando a relação entre a percepção cognitiva visual e a linguagem.
} 
que compõem aquela cena. ${ }^{3}$ Nessa perspectiva, a atenção e a relevância estão intrinsecamente relacionadas com a escolha temática feita pelo falante/escritor.

Como se pôde ver, há uma interação muito significativa entre a estrutura temática e estrutura de informação, dependentes de uma organização sintática, que, por sua vez, está sujeita a capacidades e restrições de ordem cognitiva.

\section{ALGUNS RECURSOS SINTÁTICOS}

Do ponto de vista da estrutura da informação, os participantes e os processos verbais podem ser categorizados como elementos dados ou novos. A informação do texto é apresentada em um fluxo estruturado para que o discurso seja funcional para a comunicação. Em uma sentença, o tema é normalmente um elemento dado e novas informações tendem a aparecer como rema. Portanto, ao escolher o elemento tema para sua proposição, o escritor atende a pressões do discurso para a distribuição da informação dada e nova. Existe uma grande variedade de recursos sintáticos disponíveis para escritores e falantes de inglês para atender a essas pressões do discurso. Mesmo sendo o inglês considerado tipologicamente uma língua SVO, existem várias possibilidades de reorganização dos elementos básicos da sentença (S, V, O/C, A). McCarthy (1991) exemplifica alguns arranjos sintáticos envolvendo deslocamento, ou seja, várias formas através das quais se podem colocar diferentes elementos na posição inicial, ou na posição final, de uma sentença.

3. a) The Guardian, Joyce reads.

\section{OSV \\ Deslocamento do objeto à esquerda}

b) Sometimes Joyce reads The Guardian.

ASVO

Deslocamento do adjunto à esquerda

c) It is The Guardian Joyce reads.

$\mathrm{It}+\mathrm{be}+\mathrm{C} / \mathrm{O}+\mathrm{SV} \quad$ Clivagem

d) What Joyce reads is The Guardian.

$\mathrm{Wh}+\mathrm{SV}+\mathrm{b}+\mathrm{C} / \mathrm{O} \quad$ Pseudo-clivagem

e) She reads The Guardian, Joyce.

$\mathrm{S}$ (pronome) VOS (substantivo) Deslocamento do sujeito à direita

(McCARTHY, 1991: 51-52)

3 Outros fenômenos linguísticos que relacionam especificamente o uso da linguagem à nossa capacidade cognitiva de atenção, são, por exemplo, topicalização e estrutura narrativa: veja Tenuta e Lepesqueur (2011). 
O autor afirma que algumas dessas estruturas são, por exemplo, raramente encontrados em gramáticas e em livros didáticos, o que não contribui para que o aprendiz se familiarize com elas. E essas diferentes estruturas sintáticas constituem recursos linguísticos preciosos, disponíveis na língua, que servem para atender a demandas do discurso em termos de estrutura de informação, uma vez que se encaixam em diferentes contextos discursivos. 3. (a) poderia ser uma resposta ao The Mirror, Joyce reads. What about The Guardian? 3.(c) ou 3.(d), alternativamente, poderiam integrar respostas negativas para Joyce reads the Mirror, right? No.... Além disso, podemos reforçar que o uso de estruturas sintáticas distintas determinam arranjos de atenção e foco específicos, que se relacionam à estrutura temática, como: 3.(a) diz algo sobre The Guardian e 3.(e) diz algo sobre Joyce.

O elemento sintático que constitui normalmente o ponto de partida para o desenvolvimento da sentença é o sujeito da oração e esse sujeito relaciona-se, prototipicamente, a uma informação dada. Chafe (1995) afirma que o sujeito sintático tem carga informacional leve, o que justamente o torna adequado como esse ponto de partida da mensagem. ${ }^{4}$ Esse autor propões um sistema tripartite da estrutura da informação que envolve 3 categorias de ativação (elementos ativos, semiativos e inativos). Nesse sistema, temos os elementos que são dados, os que são acessíveis e os que são novos. A informação dada é a considerada pelo falante como conhecida pelo ouvinte, portanto já ativa, enquanto a informação nova estaria tendo uma primeira entrada em sua mente, estando sendo ativada naquele instante, e a informação acessível, ou semiativa, é definida como "a) tendo estado ativa em um momento anterior no discurso; b) estar diretamente associada a uma ideia que está ou esteve ativa, ou c) estar associada ao ambiente não-linguístico da conversação" (CHAFE, 1995: 86). Esse autor apresenta os resultados de um estudo em que $81 \%$ dos sujeitos sintáticos que analisou, que eram tema (ponto de partida da mensagem), expressaram informação dada, e 16\%, informação acessível. Apenas 3\% daqueles sujeitos sintáticos trazia informação nova. A informação nova trazida por esses 3\% o autor analisou como sendo de um tipo especial, trivial, pois expressam participantes que não são relevantes no contexto do discurso e, em geral, não recebem outra menção subsequente. Carroll e Shea (2007) explicitam essa visão de Chafe, afirmando os sujeitos sintáticos, portanto, tendem transmitir este tipo de informação: um referente ativo, identificável, no foco atual de atenção e consciência; ou um referente acessível, por ser inferido a partir do contexto situacional.

4 Entretanto, de acordo ainda com Chafe, o fato de o elemento ter carga informacional leve não significa necessariamente que seja um elemento dado. 
Nessa perspectiva teórica, a escolha do elemento tema (por exemplo, a decisão tomada pelo falante/escritor se o tema é ou não o sujeito sintático da sentença) é feita com base em exigências da comunicação. Portanto, ao escolher o elemento tema de uma proposição, esse falante/escritor está seguindo os princípios discursivos da estrutura de informação. Levando-se em conta esta interação entre as estruturas sintática, informacional e temática, torna-se evidente a forma como a sintaxe, a semântica e o discurso estão interligados. Novamente, a fim de se atenderem a variadas pressões de discurso, o usuário da língua, principalmente como escritor, é levado a produzir construções diversificadas (GOLDBERG, 1995; 1998) ou a realizar movimentos sintáticos (voz passiva, clivagem, deslocamento). Estes movimentos permitem diferentes arranjos na distribuição de informação, enquanto o conteúdo proposicional das sentenças permanece inalterado (McCARTHY, 1991):

4. a) Larry cooked this stew last night.

b) This stew was cooked by Larry last night.

c) It was Larry who cooked this stew last night.

d) Last night, Larry cooked this stew.

e) Last night, it was Larry who cooked this stew.

Embora a proposição semântica tenha permanecido a mesma nas frases 4.(a) a 4.(e), elas apresentam diferentes elementos como tema, gerando variados arranjos sintáticos: o uso de voz passiva, ou a utilização de deslocamento, de estrutura clivada ou pseudo-clivada. Essas diferentes estruturas encaixam-se em contextos comunicativos também variados. Por exemplo, em resposta a What did Larry cook last night?, as formas encontradas em 4.(a) e 4.(d) são as mais adequadas. Em um outro contexto, What about this stew?, a escolha de this stew, como sujeito seria apropriada, por exemplo, como na estrutura na voz passiva em 4.(b).

Observe o seguinte exemplo:

5. FALANTE A: What did the rain do?

FALANTE B: The crops were destroyed by the rain.

(WIDDOWSON, 1978:25 apud CANALE,1983:10)

Segundo Canale, a resposta do falante $B$ apesar de ser apropriada nas perspectivas gramatical e sociolinguística, não responde bem a pergunta do falante $\mathrm{A}$, pois não tem 
com essa pergunta um elo apropriado no nível da organização discursiva típica de textos em língua inglesa. Esse elo se dá em termos de a informação compartilhada, presente no tópico, preceder a informação nova, que em geral está no comentário.

Esse princípio do discurso restringe a forma gramatical dos enunciados que podem ocorrer com a pergunta de A, filtrando formas compatíveis das incompatíveis, independente de serem apropriadas gramatical e sociolinguisticamente. Essa interação de regras gramaticais, sociolinguísticas e discursivas é sugestiva da complexidade da competência comunicativa... (CANALE, ${ }^{5}$ 1983:10).

\section{A INTERLÍNGUA DOS APRENDIZES}

Rutherford (1987) analisa algumas das características da interlíngua dos aprendizes de inglês como L2 e enfatiza a importância de se trabalhar com esses aprendizes para se promover a consciência de quaisquer diferenças significativas entre essa interlíngua e as formas da língua-alvo. Os aspectos linguísticos discutidos por Rutherford (1987) e verificados em nossa pesquisa estão relacionados com recursos sintáticos e padrões que são importantes para os usuários do inglês tenham sucesso na produção de textos informacionalmente bem estruturados, sensíveis às pressões do contexto discursivo, facilmente processados ou entendidos.

Tornar-se consciente de tais aspectos gramaticais do sistema da língua alvo é especialmente recomendado para os aprendizes adultos, que já passaram por um processo de instrução formal em L1 e podem se beneficiar de uma abordagem que utilize de metalinguagem relacionada à L2. Este trabalho gramatical pode, potencialmente, ajudar esses aprendizes na aquisição da habilidade da escrita. Em relação a este ponto, podemos verificar o comentário de Richards (1990):

Se, por um lado, as regras do discurso oral são adquiridas através a conversação e não requerem instrução, por outro, as regras do discurso escrito são amplamente aprendidas através da instrução e da prática. (...) O objetivo da língua escrita é passar informação de forma precisa, efetiva e apropriada; e, para isso, a linguagem escrita tem de ser mais explícita que o discurso oral. ${ }^{6}$ (RICHARDS, 1990: 100-101).

\footnotetext{
5 No original: This principle of discourse restricts the grammatical form of utterances that can cooccur with A's question, filtering out compatible forms from incompatible ones, regardless of their grammatical and sociolinguistic appropriateness. This interaction of grammatical, sociolinguistic and discourse rules is suggestive of the complexity of communicative competence...

6 No Original: Whereas the rules of spoken discourse are acquired through conversation and do not require instruction, the rules of written discourse are largely learned through instruction and practice. (...) The goal of written language is to convey information accurately, effectively, appropriately; and to do this, written language has to be more explicit than spoken discourse.
} 
Uma das características da interlíngua de aprendizes de inglês como L2 discutidas em Rutherford (1987) é a tendência apresentada por esses aprendizes de colocarem os constituintes da sentença em sua posição básica (ordem básica SVO), dentro de uma estrutura temática não marcada da sentença. Isso significa que os aprendizes têm a tendência a não aplicar movimentos sintáticos, ou seja, eles mantêm um alinhamento entre semântica e sintaxe, no qual as relações semânticas são expressas diretamente dentro do arranjo sintático canônico da sentença. No entanto, a fluência em qualquer língua implica, entre outros fatores, em se ser capaz de mover os constituintes da sentença, gerando correspondência não direta entre sintaxe e semântica, como, por exemplo, através do uso da voz passiva ou de outra estrutura movida.

Para melhor poderem responder às pressões do discurso em uma interação comunicativa, os aprendizes de inglês cuja língua materna é o português necessitam ser ensinados, por exemplo, que o sistema dessa língua alvo, em qualquer oração independente, a presença de um sujeito sintático:

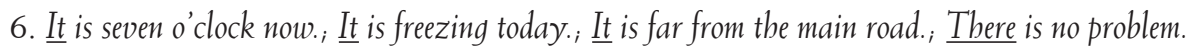

Os aprendizes também precisam ser ensinados que a fluência em inglês exige familiaridade com mudanças sintáticas geradas por meio de deslocamentos, como já mencionado, de extração e extraposição. Por exemplo, a partir de 7.(a), que é uma sentença básica (fora de qualquer contexto discursivo), obtemos as estruturas movidas 7.(b), 7(c) e 7.(d):

7. a) To detect such particles without a microscope is difficult.

b) It is difficult to detect such particles without a microscope.

c) Such particles are difficult to detect without a microscope.

d) Without a microscope such particles are difficult to detect.

(RUTHERFORD, 1987)

Em 7.(b), podemos dizer que temos extraposição: o elemento sujeito de is difficult foi deslocado para a direita desse predicado e seu lugar anterior foi ocupado pelo dummy it. Essa estrutura com dummy it torna-se mais facilmente processável do que a estrutura não movida, que tem um sujeito formalmente mais complexo. Em 7.(c), temos extração e deslocamento. O objeto de detect foi extraído a partir da estrutura infinitiva e levado para a posição de sujeito. Em 7.(d), encontramos deslocamento: a locução prepositiva without a microscope assume posição inicial. 
Em 7.(a), sintaxe e semântica estão alinhadas, enquanto, em 7.(d), estão em desalinhamento máximo. Estes tipos de movimento, ou, se preferirmos, essas construções opcionais, também ocorrem em português, com exceção da obrigatoriedade do sujeito sintático em 7.(b). É importante, no entanto, saber se os aprendizes de inglês, falantes de português, usariam essas construções alternativas para tornar seus textos em inglês mais fluentes, ou mais facilmente processados. Segundo Rutherford, mesmo quando a língua materna do aprendiz permite algum tipo de movimento, este aprendiz pode rejeitar a estrutura movida no inglês. Isso é condizente com o que Canale (1983) afirma em relação ao ensino de estratégias de comunicação:

Apesar de uma estratégia geral como a paráfrase ser na verdade universal e ser usada para a comunicação na primeira língua, deve ser mostrado aos aprendizes como essa estratégia pode ser implementada na segunda língua (...) Além disso, os aprendizes devem ser encorajados a usar tais estratégias (...) e deve ser dada a eles a oportunidade de usá-las. ${ }^{7}$ (CANALE, 1983: 11)

Podemos pensar que essa mesma necessidade de se mostrar um item ou fenômeno aos aprendizes é válida em relação ao princípio da distribuição de informação no texto. Recursos e mecanismos sintáticos devem, então, ser tornados evidentes nos insumos oferecidos aos aprendizes.

Outra questão referente à interlíngua dos aprendizes é a questão das relações semânticas geradas entre o verbo principal da sentença e seus argumentos ( $\mathrm{SNs}$ ). Pode haver várias possibilidades de $\mathrm{SN}$ como sujeito sintático de uma sentença e é importante que os aprendizes percebam isso, uma vez que, mesmo havendo uma mudança no sujeito da frase, pode se manter inalterada a relação entre o verbo e seus argumentos.

Relacionado a isso, temos o fato de que o sujeito não-agentivo é outro recurso linguístico disponível para os usuários da língua inglesa para atenderem a pressões discursivas de distribuição da informação em textos. Por exemplo, podemos ter um sujeito gramatical como agente, como meta, ou como instrumento, que são alguns dos papéis semânticos disponíveis no sistema:

8. a) agente: The child broke the window with a bammer.

b) meta: The window broke

c) instrumento: The bammer broke the window.

7 No original: Although a general strategy such as paraphrase is indeed universal and used in first language communication, learners must be shown how such a strategy can be implemented in the second language (...) Furthermore, learners must be encouraged to use such strategies (...) and must be given the opportunity to use them. 
A produção de sujeito não-agentivo por aprendizes não é geralmente muito frequente (Rutherford, 1987). No entanto, se essa produção se tornasse mais frequente, poderia resultar em maior habilidade para esses aprendizes atenderem a demandas comunicativas em interações verbais. Outros exemplos de sujeitos nãoagentivos são:

9. My guitar broke a string.; This shirt buttons in back.; Ice cream keeps for a long time.; A dollar will not buy you much.

Uma outra questão ligada ao desenvolvimento da interlíngua de aprendizes pode ser ilustrada pelas seguintes sentenças:

10. a) Rome invaded the island.

b) The invasion of the island by Rome.

O desenvolvimento da interlíngua deve permitir aos aprendizes melhor elaborar seus argumentos, resultando em uma produção que seja mais variada. Mais uma vez, nessa produção, contextos específicos podem exigir, por exemplo, que eles se utilizem de substantivos deverbais. Nesse caso, seria necessário que esses aprendizes estivessem conscientes dessa outra estratégia linguística que resulta em mudança na estrutura sintática - de (a) para (b) - sem perturbar as relações semânticas existentes entre os elementos lexicais envolvidos.

Outra característica importante da interlíngua de aprendizes de inglês como L2 é a utilização excessiva de repetição lexical. Nesse caso, a sensibilização dos aprendizes para os variados recursos de coesão lexical disponíveis, tais como, a sinonímia, a anáfora, e a elipse, é muito significativa para o processo de aprendizagem. A incidência de repetição pode ser minimizada para um nível desejável, a partir de tal sensibilização.

Em suma, as relações verbo-argumento e a coesão lexical são questões essenciais relacionadas à conscientização gramatical dentro de uma visão da linguagem que seja mais global e que a língua seja pensada como um sistema vivo de comunicação. Segundo Rutherford (1987), se realmente se quer enfocar a sintaxe, a semântica e a pragmática como partes integrantes de um mesmo todo, é relevante, em uma situação específica, considerarmos o que é necessário ser feito do ponto de vista da sintaxe para se apresentar uma informação em uma determinada posição no discurso, bem como considerarmos que tipo de mudanças morfossintáticas são necessárias para se colocar ou se manter um certo elemento lexical em um contexto linguístico específico. 
Rutherford (1987) advoga a favor de Consciousness-Raising (CR), que é uma abordagem de gramática que visa a ajudar os aprendizes a se tornarem conscientes das interconexões entre a sintaxe, a semântica e o discurso. Nessa perspectiva, a conscientização da gramática é um meio para se atingir um fim e essa conscientização envolve se aliar conhecimento metalinguístico a uma abordagem de ensino de gramática voltada para o contexto.

A hipótese de noticing (SCHMIDT, 1990; 1995; 2001) é também uma proposta que vai nessa direção da conscientização de aspectos gramaticais. Schmidt postulou que os aprendizes devem se atentar para ou notar algo para adquirir esse algo. Esse autor afirma que só o que pode ser introjetado é o insumo que se tornou consciente (SCHMIDT, 1995). Segundo essa proposta, os aprendizes percebem elementos da estrutura a partir de ocorrências de língua, não a partir de regras ou princípios abstratos que tais ocorrências podem instanciar (SCHMIDT, 2001). Os aspectos linguísticos que são notados mais rapidamente são considerados mais salientes em seus contextos.

Assim, a estrutura de informação pode ser integrada a um conjunto de hipóteses sobre o processamento de sentenças no discurso e está relacionada a funções cognitivas de atenção e memória. A estrutura de informação é, portanto, potencialmente importante para a aprendizagem de uma língua. Os exercícios elaborados para este estudo tiveram como objetivo verificar a percepção que os aprendizes têm dessa estrutura relacionada com o sistema gramatical, semântico e discursivo, tudo isso impactando a comunicação.

\section{METODOLOGIA}

Um conjunto de dez exercícios foi elaborado com foco nas estruturas temática e informacional atuantes no discurso. Os exercícios foram aplicados em 46 alunos de graduação da habilitação em Inglês da Faculdade de Letras da UFMG e tiveram como objetivo checar, especificamente, a percepção desses aprendizes sobre:

a) a necessidade de se mover algum componente da oração com a finalidade de se atender a demandas discursivas específicas;

b) a relação entre a estrutura temática e a estrutura sintática da oração;

c) a referenciação adequada e o uso de elementos coesivos em um texto;

d) a estrutura adequada da oração em termos da ordem SVO e a obrigatoriedade de um sujeito sintático; 
e) o fato de que um mesmo conteúdo proposicional poder ser expresso através de diferentes estruturas nominais e verbais e

f) a gramaticalidade de sentenças com sujeitos que desempenham papéis temáticos variados.

Com a finalidade de se atingirem esses objetivos, os exercícios propostos aos aprendizes visaram a verificar se os participantes reconheciam, de forma implícita (procedimental) e/ou explícita (declarativa) ${ }^{8}$, a existência das estruturas temática e da informação nas sentenças. Os exercícios visaram a responder uma pergunta de pesquisa básica, que poderia ser formulada da seguinte forma: Estão os aprendizes cientes do princípio da distribuição da informação na língua? Além dele, e relacionado a esse princípio, os exercícios também checaram o domínio, por esses aprendizes, de vários mecanismos sintáticos disponíveis no sistema da língua inglesa para utilização em caso de demandas discursivas específicas, relacionadas às estruturas informacional e temática, e que evidenciam a relação entre linguagem e cognição através de processos de atenção e foco. Os seguintes tipos de exercícios foram desenhados para a pesquisa:

1. Exercício(s) sobre o princípio da informação (dado/novo): para checagem da percepção da necessidade de se moverem constituintes da sentença por pressões do discurso.

2. Exercício(s) sobre coesão lexical: para checagem da percepção do estabelecimento adequado da correferência, assim como checagem da identificação de mecanismos coesivos de um dado referente.

3. Exercício(s) sobre a ordem SVO: para checagem da percepção de problemas com uma estrutura em termos da ordem SVO.

4. Exercício(s) envolvendo Clusters proposicionais: para checagem da percepção do fato de que um mesmo conteúdo proposicional pode ser expresso através de diferentes estruturas nominais e verbais.

5. Exercício(s) envolvendo apresentação do tema: para checagem da percepção das mudanças ocorridas através de diferentes arranjos sintáticos na estrutura da sentença quando um determinado elemento temático é escolhido.

6. Exercício(s) envolvendo sujeitos não-agentivos: para checagem da percepção da gramaticalidade de sentenças com sujeitos gramaticais que desempenham papéis temáticos variados.

8 Os conceitos de conhecimento declarativo e procedimental são encontrados em Johnson (1994). 
Os exercícios foram aplicados e as respostas fornecidas pelos aprendizes foram analisadas e categorizadas em termos dos principais objetivos da pesquisa.

Na próxima seção, discutiremos a aplicação desses exercícios e as respostas dadas a eles, que constituíram os resultados da pesquisa.

\section{ANÁLISE DOS DADOS}

Nesta seção, apresentamos os dados coletados no estudo. Realizamos análises relacionadas aos seguintes temas: a interação entre a estrutura da informação e a estrutura temática; cluster proposicional e nominalizações; sujeitos sintáticos com papéis temáticos variados; a obrigatoriedade do sujeito sintático; elementos coesivos; um mesmo conteúdo proposicional expresso por diferentes arranjos temáticos.

\subsection{A interrelação entre a estrutura da informação e a estrutura temática}

Com a finalidade de se checar a percepção da interrelação entre a estrutura da informação e a estrutura temática em um texto, o seguinte exercício foi aplicado aos participantes da pesquisa:

11. Which passage below is of easier understanding (more fluent reading)?

a) The late English artist and filmmaker Derek Jarman once met a friend on London's Oxford Street and complimented bim on bis beautiful yellow coat. His friend replied that he bad bought it in Tokyo, where it was not considered yellow at all, but green.

b) The late English artist and filmmaker Derek Jarman once met a friend on London's Oxford Street and complimented bim on bis beautiful yellow coat. In Tokyo, where his friend bought the coat, it was not considered yellow at all, but green.

(Em: www.bbc.com/future/story/20120427)

$74 \%$ dos participantes marcaram a opção correta, que é a passagem (a): nessa passagem, a informação dada está em alternância com informação nova, que é uma estruturação de informação apropriada. Houve, por parte dos aprendizes, um reconhecimento do princípio da distribuição da informação no discurso, que 
revela algum conhecimento implícito da questão. No entanto, o índice de acerto foi ainda considerado baixo dado o fato de os aprendizes terem tido $50 \%$ de chance de acerto (uma vez que só havia duas opções).

Apenas 13\% dos aprendizes foram capaz de explicar adequadamente sua opção pela passagem (a), o que revela que o conhecimento explícito desse princípio não foi significativo entre os participantes. Os alunos de graduação, informantes da pesquisa, mostraram, assim, pouco conhecimento metalinguístico da questão, o que pode ser considerado uma limitação da sua competência linguística, principalmente se levamos em conta o fato que são todos da habilitação em Inglês.

\subsection{Cluster proposicional e nominalizações}

Um exercício envolvendo cluster proposicional teve também o propósito de checagem do conhecimento da estrutura da informação, mas envolvendo estruturas nominalizadas. Esse exercício era composto de poucos itens lexicais e instruções que, primeiro, levavam o participante, através do uso de fórmulas, a criar algumas estruturas nominalizadas com arranjos temáticos variados, que continham todos esses itens. Esse passo da atividade visou exatamente à sensibilização para diferentes possibilidades de expressão de um conteúdo proposicional similar. Por exemplo:

12. a) Ann clean room broom

Estas são possíveis produções:

12. b) Ann's cleaning of the room with a broom, the room's cleaning with a broom by Ann; a broom cleaning of the room by Ann.

Como segundo passo para a atividade, os participantes foram levados a escolher uma das nominalizações criadas para se encaixar em um contexto linguístico específico.

$39 \%$ dos participantes fizeram uma escolha temática nominalizada mais apropriada para o contexto fornecido, pois considerou, mesmo que por meio de um conhecimento implícito, a necessidade de uma distribuição adequada da informação. Essa escolha temática foi Ann's cleaning of the room with a broom, que atendeu ao padrão (b) descrito por McCarthy, já mencionado neste texto, segundo o qual o "tema de uma sentença tem o mesmo conteúdo referencial do tema da sentença seguinte". O tema das sentenças anteriores à estrutura em foco no exercício continha Ann. 
Em comparação com o que foi discutido no item 7.1, a porcentagem dessa escolha adequada para um determinado contexto foi menor, o que confirma a hipótese de que, havendo mais opções, o índice de acerto da escolha temático/ informacional cai: aqui foram apresentadas ao aprendiz 3 opções, em oposição às 2 opções do exercício referido em 7.1.

Neste caso, apenas $2 \%$ desses participantes foram capaz de prover uma explicação razoável para a escolha que fizeram, i.e., muito poucos aprendizes mostraram ter algum conhecimento explícito do princípio da distribuição de informação no texto.

\subsection{Sujeitos sintáticos com papéis temáticos variados}

Quanto à percepção, pelos aprendizes, da gramaticalidade de sentenças com sujeitos sintáticos desempenhando papéis semânticos (ou temáticos) variados, os aprendizes tenderam a não considerar tais sentenças como gramaticais, como a seguir:
13. a) This purse buttons back.
b) My keyboard broke a key.
c) Weapons kill.

Apenas 13\% dos aprendizes julgaram gramatical a sentença 13.(a) e $32 \%$, a sentença 13.(b). $65 \%$ foi o índice de reconhecimento de 13.(c) como gramatical. Apesar de os sujeitos sintáticos nessas sentenças não serem agentes, as sentenças são aceitáveis em inglês. Os aprendizes, no entanto, têm dificuldade em reconhecer essa gramaticalidade, até mesmo quando são encontradas estruturas correspondentes em sua língua materna, como é o caso de 13.(b) e 13.(c). Esse resultado revelou que eles, em geral, não estão familiarizados com sujeitos sintáticos desempenhando papéis temáticos variados. Esse fato aponta na direção de que seja pouco provável que esses aprendizes usarão, em suas produções, quando necessário, sujeitos nãoagentivos com os quais não estejam familiarizados.

\subsection{A obrigatoriedade do sujeito sintático}

Em relação à agramaticalidade de sentenças nas quais não haja um sujeito sintático, usamos a seguinte passagem nos exercícios: 
14. In Brazil are many cities to visit. One of them is Belo Horizonte. Is bere where is going to be one of the places that Brazil team will play during the World Cup.

$33 \%$ é a porcentagem de aprendizes que não identificou a fonte da agramaticalidade nessa passagem contendo sentenças sem a presença do sujeito sintático. Essa pode ser considerada uma porcentagem alta se levamos em conta que esse é um traço muito básico da língua inglesa e que os participantes da pesquisa já estão em um nível intermediário de seu aprendizado e já tiveram um período considerável de instrução formal na língua alvo.

\subsection{Elementos coesivos}

Em relação aos mecanismos coesivos disponíveis na língua inglesa, os aprendizes também tiveram problemas para identificar unidades como sendo elementos coesivos no texto. Por exemplo, na passagem:

15. Buenos Aires now bas more boutique botels than you can shake a polo whip at. Unfortunately, it also bas surging rates of inflation that now puts them out of reach for more budget-conscious visitors. So where does this leave the traveler who wants a place with a comfy bed (...) (Em: http://www.guardian.co.uk/travel/2012/apr/25/top-10-hotels-buenos-aires)

O elemento com função coesiva this refere-se a toda uma situação descrita antes do seu aparecimento no texto; é, portanto, um elemento anafórico que tem como correferente um trecho do discurso, e não apenas um item lexical. Nessa checagem, apenas 5\% dos aprendizes foram capaz de indicar corretamente a parte do texto à qual o pronome sublinhado se referia. Isso significa que a identificação de elementos coesivos que se referem a trechos maiores do texto pode representar um obstáculo para os aprendizes, provavelmente impactando negativamente a compreensão total de um texto. Isso torna evidente o fato de que ainda é necessário se trabalhar no sentido da conscientização dos aprendizes da função coesiva de unidades linguísticas diversas, com a finalidade de ajudá-los também a produzirem textos que sejam mais fluentes e melhor estruturados do ponto de vista da distribuição da informação.

Em textos escritos percebidos como melhor elaborados, ou mais maduros, elementos dados geralmente não aparecem simplesmente como repetições dos itens lexicais plenos, porém, ocorre a utilização de uma variedade de formas (nominais, pronominais, verbais, elipses) com conteúdo referencial similar. Portanto, os 
aprendizes devem estar preparados tanto para a identificação, quanto para a produção dessa variedade.

\subsection{Um mesmo conteúdo proposicional expresso por diferentes arranjos temáticos}

Focalizando nas seguintes sentenças

\section{Someone took it to my classroom.}

It was taken to my classroom.

checamos a consciência dos aprendizes do fato de que um mesmo conteúdo proposicional pode ser expresso através de diferentes arranjos temáticos, em diferentes estruturas sintáticas. Com respeito a essa questão, $47 \%$ dos aprendizes puderam identificar as mudanças sintáticas de uma sentença em relação à outra. Esse resultado revela que aproximadamente metade dos participantes da pesquisa pôde explicar as mudanças ocorridas utilizando-se de metalinguagem apropriada para tal, ou seja, mencionou, de alguma forma, a reestruturação da sentença em uma construção passiva. No entanto, isso também significa que a outra metade não foi capaz de produzir explicação semelhante.

Quando os aprendizes foram solicitados a escolher uma entre essas duas sentenças para ocupar um determinado contexto linguístico, $72 \%$ deles fizeram a escolha mais apropriada em termos do princípio da distribuição da informação. Apesar de a maioria parecer estar consciente do impacto que os diferentes arranjos sintáticos produzem no discurso, ainda tivemos um número significativo de aprendizes que não notaram essa situação, especificamente se consideramos que eles tinham $50 \%$ de chance de prover a resposta adequada, uma vez que havia apenas duas alternativas para a escolha.

Quando os aprendizes tiveram que explicar o porquê de sua escolha, dos 46 participantes, $22 \%$ proveram explicação que envolveu, de alguma forma, menção à necessidade de se ligar o elemento que inicia a segunda sentença com o que termina a sentença anterior, por vezes, mencionando a referenciação. Nenhum dos aprendizes usou a metalinguagem específica da estrutura temática, em termos de tema e rema.

\section{CONSIDERAÇÕES FINAIS}

Os resultados nesta pesquisa apontam para o fato de que a maioria dos estudantes analisados, que são alunos de graduação da habilitação em Inglês de um 
curso de Letras, de nível intermediário ou pós-intermediário de proficiência na língua alvo, não possuem um conhecimento explícito do princípio da informação atuando na estruturação do discurso e têm, também, pouco conhecimento implícito desse princípio. Os resultados mostram ainda que esses aprendizes de inglês como L2 apresentaram algumas das características discutidas por Rutherford como sendo comuns a esse tipo de aprendiz: primeiro, eles tiveram dificuldade na identificação da correferência de elementos coesivos; segundo, somente cerca de metade dos aprendizes foi capaz de identificar a falta do sujeito sintático, que é obrigatório em inglês; finalmente, eles reconheceram poucos sujeitos não-agentivos como gramaticais, o que reduz suas chances de atenderem às pressões discursivas em alguns contextos, por não serem capazes de utilizar elementos temáticos variados ao produzirem seus textos, suas mensagens. Outras pesquisas teriam de ser feitas, em outros ambientes acadêmicos brasileiros para confirmar, mas é nossa hipótese que a situação não deve ser diferente nesses outros contextos.

Desse ponto de vista, os aprendizes de L2, não sendo falantes nativos, nem sempre percebem como a informação é melhor distribuída para se ser fiel à saliência de elementos em certos contextos linguísticos. Por outro lado, quando eles parecem notar esses aspectos de saliência e foco, eles não estão equipados declarativamente, ou seja, com conhecimento metalinguístico, para falar sobre os processos envolvidos na construção e na interpretação das sentenças. Esse fato se tornou evidente, pois os aprendizes frequentemente não foram capazes de explicar adequadamente que mudanças ocorreram, ou que construções alternativas foram usadas nos diferentes arranjos linguísticos.

Nesta pesquisa, focalizamos um sistema gramatical em sua complexidade, pois esse sistema tem a gramática relacionada ao discurso e à cognição. Nessa perspectiva, as interações verbais em um contexto de uso emergem da forma como a organização do discurso propriamente se relaciona ou depende das capacidades cognitivas humanas gerais. Os aprendizes precisam ser conscientizados do fato de que as demandas discursivas afetam a sintaxe; eles não estão cientes da natureza dessa relação entre sintaxe e discurso, assim como têm pouca ciência ou percepção da relação entre esses sistemas e a cognição.

$\mathrm{O}$ ensino de L2 pode ser melhorado se os aprendizes forem levados a perceber esses aspectos do sistema linguístico. Considerando-se que há fenômenos específicos da língua ou de seu grupo tipológico, uma das funções importantes do ensino é ajudar os aprendizes a focar sua atenção nos aspectos da língua alvo que justamente diferem da língua materna. Os aprendizes, no entanto, devem 
também ser conscientizados dos aspectos linguísticos que são determinados por princípios de preferência universais, especialmente aqueles de natureza cognitiva, tais como ao princípio da distribuição da informação enfocado neste estudo. Como Rutherford aponta, os aprendizes podem fazer uso de uma determinada forma ou movimento sintático em sua língua materna, mas não fazê-lo na língua alvo, talvez por não se sentirem seguros e preferirem se apoiar em estruturas mais básicas, não marcadas, ou com um maior alinhamento entre a sintaxe e a semântica.

Com respeito a isso, um padrão de distribuição de informação não é específico da língua e pode provavelmente ser generalizado para muitas delas, sendo, na visão de Rutherford, uma tendência geral das línguaslanguage-general tendency (RUTHERFORD, 1987: 113). Assim, mesmo ocorrendo esse padrão também na língua portuguesa (L1), torna-se necessário descobrir se ele terá de ser aprendido ou reaprendido em L2.

Além de incentivar a prática linguística de variações de formas da língua alvo que possam permitir aos aprendizes lidar com demandas discursivas variadas, reforçamos a noção de que a conscientização metalinguística também seja objeto de instrução linguística. Essa instrução é um meio de se habilitar ainda mais os aprendizes para sua produção comunicativa. Particularmente no caso dos graduandos em Inglês, a promoção desse conhecimento explícito ou declarativo do sistema da língua inglesa e de suas regras constitutivas é importante, uma vez que esses aprendizes serão, muito provavelmente, profissionais da linguagem e terão atuação como professores ou pesquisadores em alguma área da linguística. Nessa perspectiva, devemos lidar com a gramática como uma parte de um sistema, integrada ao discurso, e abordar as escolhas das formas linguísticas como, de alguma forma, condicionadas por restrições funcionais e cognitivas. Dessa forma, poderemos refletir sobre e vir a conhecer as razões por detrás das regras e as relações entre os elementos e fenômenos linguísticos.

Este estudo poderia ser expandido em algumas direções, especialmente para incluir investigação sobre a forma como os mesmos aprendizes de L2 lidam com essa questão ampla da interrelação entre sintaxe, discurso e cognição em sua língua materna.

\section{REFERÊNCIAS BIBLIOGRÁFICAS}

CANALE, M. (1983). From communicative competence to communicative language pedagogy. Language and communication. Longman. 
CARROLL, S. E; SHEA, C. (2007). Salience, focus and second language acquisition. Nouveaux cabiers de linguistique française, 28, pp. 99-106.

CHAFE, W. (1990). Some things that narrative tells us about the mind. In: Britton, B. K.; Pellegrini, A. D. (eds.), Narrative thought and narrative language. New Jersey: Lawrence Erlbaum.

CHAFE, W. (1995). Discourse, consciousness and time: the flow and displacement of conscious experience in speaking and writing. Chicago, Ill: University of Chicago Press.

GOLDBERG, A. E. (1995). Constructions: a construction grammar approach to argument structure. Chicago: University of Chicago Press.

GOLDBERG, A. E. (1998). Semantic principles of predication. In: Koenig, J. P. (ed.), Discourse and cognition: bridging the gap. CSLI Publications, pp. 41-55.

GIVÓN, T. (1992). The grammar of referential coherence as mental processing instructions. Linguistics, 30, pp. 2-55.

HALLIDAY, M.A.K. (1973). Explorations in the functions of language. London: Edward Arnold.

HALLIDAY, M. A. K. (1985). An introduction to functional grammar. Arnold, London.

HALLIDAY M. A. K. (2004). An introduction to functional grammar. London: Hodder Arnold Publication, Revised Edition.

HOPPER, P. J. (1979). Aspect and foregrounding in discourse. In: T. Givon, (ed.), Syntax and semantics. New York: Academic Press, pp. 213-241.

JOHNSON, K. (1994). Teaching declarative and procedural knowledge. In: Bygate, M.; Tonkyn, A.; Williams, E. (eds.), Grammar and the second language teacher). Hemel Hempstead: Prentice-Hall International, pp. 224-36.

LANDAU, B.; JACKENDOFF, R. (1993). What and where in spatial language and spatial cognition. Behavioral and brain sciences. Cambridge University Press, 16, pp. 217-261.

LANGACKER, R. W. (1987). Foundations of cognitive grammar: theoretical prerequisites. Stanford, CA: Stanford University Press. v. 1. 
LANGACKER, R. W. (2008). Cognitive grammar: a basic introduction. New York: Oxford University Press.

MacWHINNEY, B. (1977). Starting points. Language, 53, pp. 152-168.

McCARTHY, M. (1991). Discourse analysis for language teachers. Cambridge University Press.

OSGOOD, C. E.; BOCK, J. K. (1977). Salience and sentencing: some production principles. In: Rosenberg, S. (ed.), Sentence production: developments in research and theory. Hillsdale, NJ: Erlbaum, pp. 89-140.

PRINCE, E. F. (1981). Towards a taxonomy of given-new information. In: Cole, P. (ed.), Radical pragmatics. New York: Academic Press, pp. 222-55.

RICHARDS, J. C. (1990). The language teaching matrix. Cambridge University Press.

RUTHERFORD, W. (1987). Second language grammar: learning and teaching. Essex: Longman.

SCHMIDT, R. (1990). The Role of Consciousness in Second Language Learning. Applied Linguistics, 11, pp. 129-158.

SCHMIDT, R. (1995). Consciousness and foreign language learning: a tutorial on the role of attention and awareness in learning. In Schmidt, R. (ed.), Attention and awareness in foreign language learning. Honolulu, HI: University of Hawaii, Second Language Teaching \& Curriculum Center, pp. 1-63.

SCHMIDT, R. (2001). Attention. In: Robinson, P. J. (ed.), Cognition and second language instruction. Cambridge, U.K., pp. 3-32.

TALMY, L. (2000). Toward a cognitive semantics: concept structuring systems. Cambridge, MA: The MIT Press. v. 1

TENUTA, A. M.. (2001) A estrutura da informação no discurso e algumas caraterísticas da interlíngua de aprendizes de Língua Inglesa como L2. In: Revista Linguagem e Ensino, Vol.4, No2,. pp.11-34.

TENUTA, A. M.; LEPESQUEUR, M. (2011). Aspectos da afiliação epistemológica da linguística cognitiva à psicologia da gestalt: percepção e linguagem. Ciências \& Cognição (UFRJ), v. 16 (2), pp. 65-81. 
0 princípio funcional/cognitivo da estrutura da informação...

TOMLIM, R. S. (1995). Focal attention, voice, and word order: an experimental, crosslinguistic study. In: Downing, P.; Noonan, M. (eds.), Word order in discourse. Amsterdam: John Benjamins, pp. 517-554.

WIDDOWSON, H.G. (1978). Teaching language as communication. Oxford: Oxford University Press.

Recebido: 08/09/2014

Aceito: 28/08/2015 